\title{
Numerical investigation of aerodynamic characteristics of generic pickup trucks
}

\author{
Jenerik pikap kamyonetlerin aerodinamik karakteristiklerinin sayısal \\ olarak incelenmesi
}

\author{
Volkan ATATUG ${ }^{1}$ (D), Seyfettin BAYRAKTAR ${ }^{2 *}$ (iD) \\ 1,2Department of Naval Architecture \& Marine Eng. Faculty of Naval Architecture \& Maritime, Yildiz Tech. Univ. Istanbul, Turkey. \\ volkan.atatug@gmail.com, sbay@yildiz.edu.tr
}

Received/Geliș Tarihi: 29.11.2018, Accepted/Kabul Tarihi: 03.07.2019

* Corresponding author/Yazıșllan Yazar

doi: $10.5505 /$ pajes.2019.43778 Research Article/Araștırma Makalesi

\begin{abstract}
In the present study, aerodynamic properties of modified generic pickup trucks were investigated by means of finite volume method. Steady, three-dimensional and turbulent flows over the pickup trucks were solved by standard k-epsilon turbulence model. An experimentally investigated two-dimensional pickup truck found in the open literature was used as a benchmark case and some modifications were done on it by closing the sides of the bed first. Then a tonneau was used to close the top of the box and finally, a canopy was used to cover the box completely from the tailgate to the cab roof. Simulations reveal that such modifications that were done on the reference case improve the aerodynamic characteristics of the vehicles in terms of drag coefficient. With respect to the original case, the drag coefficient reduces approximately 50\%, 30\% and 20\% by using a canopy, a tonneau and closing all sides except top of the bed. Such decreases in drag coefficient was achieved because every modification prevents the flow separation more effectively around the bed and behind the cab. Regardless of the shape of the bed, the drag coefficient decreases with increasing Reynolds (Re) number up to $R e=120 \times 10^{3}$. It seems that this is the critical Reynolds number since drag coefficient does not change considerably with Re any more.
\end{abstract}

Keywords: Aerodynamics, Computational fluid dynamics, Ground vehicles, Pickup truck, Drag, Lift

\section{Introduction}

As a subcategory of fluid dynamics, aerodynamics deals with the flow of gaseous, particularly air that passes over the objects like aircrafts, trains, ships, high-rise buildings, wind turbines. It becomes the major research area in several industries such as automotive, construction, energy and marine. There are several aspects of problems that should be taken into account in aerodynamics. When any gaseous past an object it applies aerodynamic forces called drag and lift forces on it and affects its motion. Up to now lots of studies have been reported for reducing the drag coefficients of bodies due to its importance. For instance, at a highway speed of $100 \mathrm{~km} / \mathrm{h}(62 \mathrm{mph})$ aerodynamic drag comprises around $62 \%$ of the power required to propel a typical heavy truck. Some active and passive flow control methods have been proposed to reduce the drag coefficient. Using cab shaping, deflectors mounted to the cab, fairing on the front and end sides of the trailer, extenders, rounding of the front edge of the body, gap-seals between the tractor and the trailer, side skirts for the trailer and rear boat tailing, etc. can be regarded as passive flow control methods
Öz

Bu çalıșmada, modifiye edilerek oluşurulmuş kamyonetlerin aerodinamik özellikleri sonlu hacimler metodu ile incelenmiștir. Kamyonetler etrafindaki daimi, üç-boyutlu ve türbülansl aksşlar standart k-epsilon türbülans modeli ile çözülmüstür. Açı literatürde bulunan ve deneysel olarak iki-boyutlu-olarak incelenmiş bir kamyonet referans alınarak, kasası üzerinde bir takım modifikasyonlar yapılmıștır. Bunun için, kasanın yanlarının dıșında, üst kısmı da düzlemsel bir yüzeyle örtülmüștür. Son olarak, kasanın üstü, yanlarıyla beraber kamyonet kasasından kabin üst yüzeyine kadar her tarafindan tamamen kapatılmıştır. Yapılan simülasyonlar, referans araç üzerinde yapılan değișikliklerin, direnç katsayısı dikkate alındığında, araçların aerodinamik karakteristiklerini iyileștirdiğini ortaya koymuştur. Orijinal duruma nazaran aracın kabinden kasanın üstüne kadar kaplanmasıyla \%50, kasanın arka, üst ve yanlarının kapatılmasıyla $\% 30$ ve sadece kasanın arka ve yanlarının kapatılıp üst tarafının açık bırakılmasıyla direnç değerinde, \%20 düșüș sağlanmıștır. Dirençteki bu azalmaların sebebi, kasa etrafinda ve kasa ile kabin arasındaki bölgede akıș ayrılmasının önlenmesidir. Kasanın șekli ne olursa olsun, direnc katsayısı Reynolds (Re) sayısının Re $=120 \times 10^{3} \mathrm{e}$ kadar arttırlmasiyla azalmıștır. Bu değerden sonra direnç değerleri Re sayısıly artık çok fazla değișmediği için bu değerin kritik Reynolds sayısı olduğu görülmüștür.

Anahtar kelimeler: Aerodinamik, Hesaplamalı akıșkanlar dinamiği, Kara vasıtası, Pikap kamyonet, Direnc, Kaldırma

[1],[2]. In addition to such passive techniques, some active flow control methods have been suggested through the years [3]. However, the latter methods in the industry are quite rare. It was revealed that a combination of better front-end aerodynamic design together with add-on devices significantly reduce aerodynamic drag [4]. Effects of air deflector on the flow field around full-scale heavy-duty trucks were investigated numerically for various yaw angles [5]. Large eddy simulation (LES) studies revealed that the aerodynamic coefficients depend on yaw angles and vehicle geometry in which wind deflector deflects the air over the truck cabin and reduces drag coefficient almost by $5 \%$. Besides, various innovative add-on devices were proposed. Using an air deflector on the cabin, a six vortex-trap panels at forward facing surface of the trailer and a vortex stake at 30 degrees at the rear part of a trailer providing a mini skirt device reduced the total drag on the truck by $21 \%$ [6].

As of May 2018, approximately twenty-three million ground vehicles are officially registered in Turkey. It was figured out that $54 \%$ of them were automobiles, $16 \%$ were trucks and $14 \%$ were motorcycles while the others were tractors, heavy trucks, 
buses and minibuses and special purpose vehicles [7]. The report makes clear that the second most popular road vehicles in use in Turkey were the trucks as their ratio to the overall vehicles was not different in most industrialized countries. For instance, the ratio of the light trucks to the overall vehicles in United States was 13\% in 2015 [8]. Nevertheless, bluff and squared-back road vehicles such as light or heavy trucks and buses have received very little attention in the relevant literature because of the complexity of flow field. Open box behind the pickup truck results strong interactions of the wake flow leaving the cab with the open box and therefore, the flow field around a pickup truck is more complex than the flow field around, for instance, a sedan car or any sport utility vehicle (SUV). From the aerodynamic drag point of view it can be implied that the pickup trucks have generally the higher drag coefficients than the other types of vehicles due to such complex flow fields. Typically, the drag coefficient of a pickup truck of any automaker is in the range of 0.46-0.49 while for a typical SUV it is between 0.41 and 0.44 . For a typical sedan car the drag coefficient changes between 0.32 and 0.34 . Considering the limited energy sources and strict regulations on emissions aerodynamic performances of pickup trucks will become increasingly more important not only for the automakers but also for the end-users. High aerodynamic drag coefficients for pickup trucks imply that the aerodynamic performance should be improved [9]. To close the gap in that area a series of numerical investigations were performed for a $1 / 12$ pickup truck model to get the detailed data on the pressure and velocity fields at various locations near the truck [10]. Basically, two regions of vortex structures were identified in the wake. The larger one rotates about a horizontal axis above the truck bed as the other comprising of two symmetric vortex streets behind the tailgate. Effects of some add-on devices such as air dam and canopy shaped bed on the drag reduction were analyzed by means of computational fluid dynamics (CFD) simulations and experimental measurements [11]. It was reported that an air dam and a canopy enable $21 \%$ savings in terms of fuel consumption. It was claimed that by changing the design of the bed the drag can be reduced for a light pickup truck [12]. It was shown that the bed height is most important factor when the truck has a short bed. For the long bed, a dominant reverse flow was determined in the wake region in which the size and the existence of such reverse flow depends upon the bed geometry. As applied to some automobiles and SUVs, a rear flap might be installed on a pickup truck. Both experimental and numerical results imply that when a rear flap is placed on the rear part of a roof, the flap increases the cabin pressure coefficient and consequently causes the bed flow to move downward and incline on the tailgate [13]. It was concluded that the drag coefficient can also be reduced by attaching the bed flow to the tailgate and increasing length of the flap. It was seen that when the downward angle of the flap increases the drag coefficient decreases. Effects of multiple bumps placed on the rear end of the cabin roof on the overall aerodynamic drag reduction for a generic model of a commercial truck were investigated numerically [14]. It was reported that the bumps increase the cabin surface pressure coefficient and displace the attachment of the bed flow over the tailgate towards the cabin and reduce the size of the recirculating flow behind the tailgate and improve the pressure in that region. As a different approach a deflector was mounted to the top of a light pickup truck. Studies revealed that the stagnation point is removed from the front of the trailer and the aerodynamic drag of the truck can be reduced [15].

As the relevant literature survey has revealed, the bed is one of the most important parts of a pickup truck in terms of the aerodynamic drag. Hence, in the present study it is aimed to investigate the aerodynamic performances of some modified pickup trucks by changing their bed designs in terms of pressure contours, flow structure and other non-dimensional numbers such as friction, pressure and drag coefficients. Although recent developments in both experimental and numerical techniques enable researchers to deal with the flow around the prototype vehicles, it is still common to work with generic geometries that are very similar to their original counterparts. From this point of view, a generic pickup truck that was experimentally studied [1] was taken into account and several modifications were done on its bed to reveal the effects of these structural modifications on the drag coefficients and the flow field for various Reynolds numbers.

\section{Computational model}

The reference model is a light (pickup) truck that was investigated experimentally using particle image velocimetry (PIV) in two-dimensional (2D) to investigate the flow field around it [1]. As shown in Figure 1 the truck has a tailgate only at the end of the bed while the sides of the bed are directly open to the atmosphere. The main dimensions of the pickup truck under investigation are shown in Figure 1.

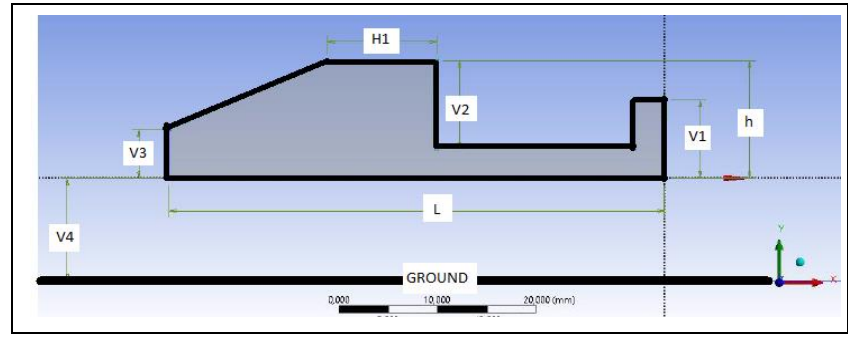

Figure 1: Dimensions of the pickup truck investigated experimentally [1].

The height of the cab from the bed base was described as $\mathrm{h}=12 \mathrm{~mm}$ while the other lengths of the pickup truck are presented in Table 1.

Table 1: Dimensions of the investigated pickup truck [1].

\begin{tabular}{cccccccc}
\hline Symbol & V1 & V2 & V3 & V4 & H1 & L & h \\
\hline Length $(\mathrm{mm})$ & 8 & 9 & 5 & 12 & 11 & 50 & 12 \\
\hline
\end{tabular}

Although the pickup truck was investigated in 2D by [1], in the present paper, it was extended into z-direction to get a three-dimensional (3D) model to mimic a real light (pickup) truck and named as Case 1. Then, various modifications were done on this reference model to investigate the effects of the bed design on the flow characteristics and aerodynamic drag performance. In the second modification, in addition to the tailgate, the sides of the truck were closed and called Case 2 . In the third case (Case 3) a bed tonneau was used to cover the truck bed and finally all sides of the bed were covered by a canopy from the tailgate to the top of the cab (Case 4) as shown in Figure 2.

Modified pickup trucks were then placed into a virtual wind tunnel to analyze their aerodynamic performances. The tunnel is a rectangular box that covers the area $-26<x / L<25$, $0.5<y / L<3.5$ and $-0.25<z / L<025$ where $\mathrm{L}$ is the length of the vehicle. 

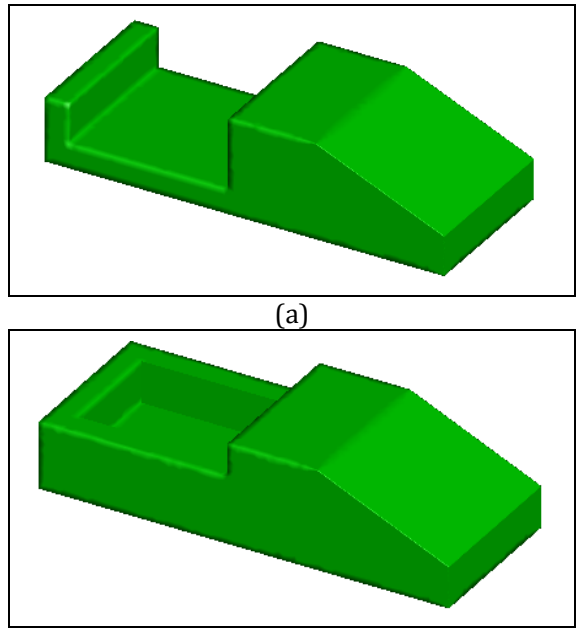

(b)

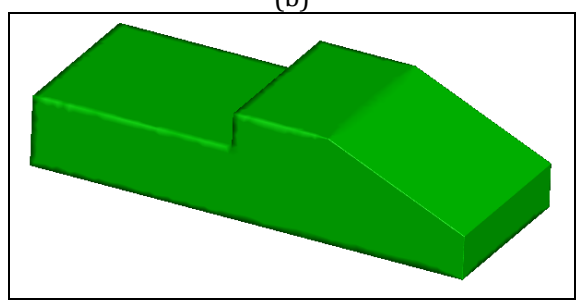

(c)

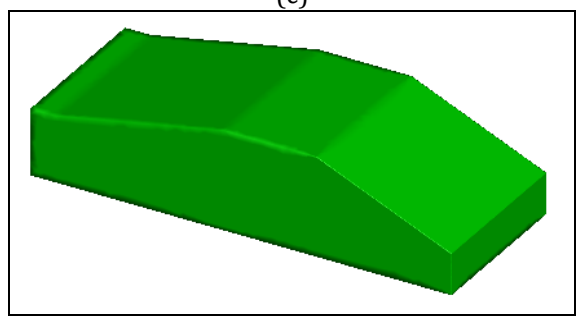

(d)

Figure 2: Reference model (Case 1). (a): and other modifications called Case 2. (b): Case 3. (c): and Case 4 (d).

The left and right sides of the computational domain in the $\mathrm{x}$ direction were assigned as velocity inlet and pressure outlet, respectively. As initial conditions the freestream velocity and turbulence intensity were specified as $0.75 \mathrm{~m} / \mathrm{s}$ and 0.07 , respectively. The entire surfaces of the truck and other remaining surfaces of the computational domain were assigned as no-slip walls. Due to low computational resources, $\mathrm{z} / \mathrm{h}=0$ was considered as symmetry plane and only half of the trucks and computational domains were analyzed. The Cartesian coordinate system was placed at the intersection of the tailgate and base. The computational domain consists of two rectangular boxes. The first one is relatively small and covers the truck and close regions in which the existence of the truck may affect the flow while the far away outer regions of the truck were covered by a larger box. The first box was discretized with very small mesh elements to capture the sharp pressure and velocity gradients in the vicinity of the truck. These are the regions where the flow separates, reattaches and forms the vortices behind and around the truck. The second box that covers the first one was divided into relatively larger volumes. A mesh independence study was performed on Case 1 with four different mesh numbers called coarse (437000 elements), normal (627060 elements), fine (822617 elements) and finally the finer mesh with 1068128 elements. It was seen that the drag coefficient $\left(C_{d}\right)$ changes $1.3 \%$ when the mesh numbers were increased approximately 30\% from the coarse mesh. A second improvement in the mesh numbers was achieved by increasing the normal mesh $23 \%$. A further improvement was done by increasing the mesh number $22 \%$. Drag coefficients change only $1.3 \%$ and $0 \%$, respectively. Due to computational limitations, all the simulations were performed by normal mesh due to small change in drag coefficient (Figure 3). It must be noted that the dimensionless wall distance, $y+$, is not lower than 90.

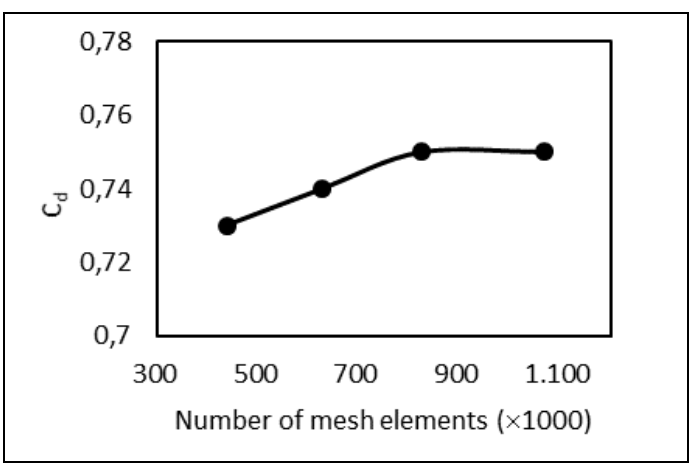

Figure 3: Mesh independence study.

As shown in Figure 4, the boundary layer over the truck was discretized with rectangular mesh elements while the working domain and truck surfaces were discretized with triangular elements.

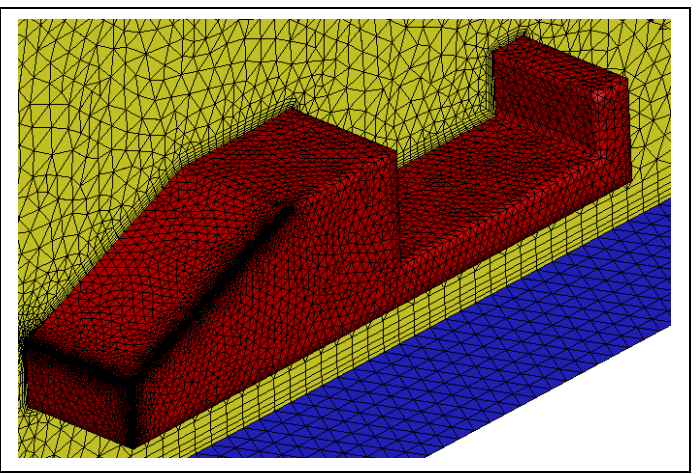

Figure 4: A close view of mesh structure around pickup truck.

The dimensionless number that represents the drag characteristics of the pickup truck is given in Equation 1.

$$
C_{d}=F_{d} /\left(0.5 \rho u_{\infty}^{2} A\right)
$$

where $C_{d}, F_{d}, \rho, u_{\infty}$ and $A$ is the drag coefficient, drag force, density of the fluid, free-stream velocity and the projected area of the vehicle, respectively. The drag force $\left(F_{d}\right)$ is comprised of two different forces in the direction of flow; the pressure and the viscous forces. The pressure force is the normal stress of the flowing air over the truck while the viscous force is generated from the shear stress of the air on the surface of the truck due to the no-slip condition. The total drag force acting on the truck is determined by integrating these forces over the entire surface of the truck. For further details, the reader can refer to [17].

Effects of truck modifications were investigated for various Reynolds (Re) numbers (Equation 2). It was defined by [1] based on the free stream velocity $\left(u_{\infty}\right)$ and height of the cab from the bed base (h). 


$$
R e=\frac{\rho u_{\infty} h}{\mu}
$$

In Eq.2, $\mu$ stands for the dynamic viscosity of the fluid. Although several computational techniques have been reported in literature such as direct numerical simulation (DNS) and large eddy simulation (LES), Reynolds-Averaged Navier-Stokes (RANS) equations were used in the present study. The relevant flow equations are the continuity (Equation 3) and the momentum equations (Equation 4).

$$
\begin{gathered}
\frac{\partial \overline{u_{i}}}{\partial x_{j}}=0 \\
\overline{u_{j}} \frac{\partial \overline{u_{i}}}{\partial x_{j}}=-\frac{1}{\rho} \frac{\partial \bar{P}}{\partial x}+v\left(\frac{\partial^{2} \overline{u_{i}}}{\partial x_{j} \partial x_{j}}\right)-\frac{\partial\left(\overline{u_{i} v_{j}^{j}}\right)}{\partial x_{j}}
\end{gathered}
$$

In Eq.3 and 4, the overbar (-) and prime ( ) refers to the mean and the fluctuating components of the velocity $(\mathrm{u})$. To relate the Reynolds stresses $\left(\overline{u_{i} v_{j}}\right)$ to the mean velocity gradients the Boussinesq hypothesis (Eq.5) was employed.

$$
\overline{-\overline{u_{i} v_{j}}}=2 v_{T} S_{i j}-\frac{2}{3} k \delta_{i j}
$$

where $v_{T}, S_{i j}, k$ and $\delta_{i j}$ is the kinetic eddy viscosity, the mean stress rate, the turbulence kinetic energy and the kronecker delta, respectively. The Reynolds stresses must be modeled by means of a turbulence model. Although several turbulence models are available, standard k- $\varepsilon$ (SKE) turbulence model [16] was preferred in the present study because it was reported that SKE turbulence model can be used for aerodynamics of the ground vehicles with high accuracy [18]. The governing equations of SKE turbulence model are the turbulence kinetic energy $(\mathrm{k})$ and its dissipation rate $(\varepsilon)$ as given in Equation 6 and Equation 7, respectively.

$$
\begin{gathered}
\operatorname{Div}(\rho k U)=\operatorname{Div}\left(\frac{\mu_{t}}{\sigma_{k}} \operatorname{gradk}\right)+2 \mu_{t} S_{i j} S_{i j}-\rho \varepsilon \\
\operatorname{Div}(\rho \varepsilon U)=\operatorname{Div}\left(\frac{\mu_{t}}{\sigma_{\varepsilon}} \operatorname{grad} \varepsilon\right)+C_{1 \varepsilon} \frac{\varepsilon}{k} 2 \mu_{t} S_{i j} S_{i j}-C_{2 \varepsilon} \frac{\varepsilon^{2}}{k}
\end{gathered}
$$

In Equations 6 and 7, the eddy viscosity, $\mu \mathrm{t}$ is defined as;

$$
\mu_{t}=\rho C_{\mu} \frac{k^{2}}{\varepsilon}
$$

where $C_{\mu}=0.09$. Equations were solved by cell-centered finite volume method. Due to being robust for single-phase steadystate flow simulations pressure-based solver was used. In this algorithm continuity and momentum equations are solved together. Pressure and momentum terms were discretized with a second order upwind scheme while the first-order upwind scheme was used for $\mathrm{k}$ and $\varepsilon$. The simulations were based on steady-state formulation since it requires less computational resources. In the present study, a commercially available CFD package Ansys Fluent 16.0 was used on a personal computer with Intel (R) Core (TM) i7 at $2.2 \mathrm{GHz}$ CPU and 8 GB RAM.

\section{Results and discussion}

Results of the present numerical study are compared with the experimental data for $\mathrm{Re}=9000$ [1]. As shown in Figure 5 both results are in good agreement except from the bottom of the working domain to the base of the truck where relatively coarse meshes were applied. The discrepancy between two studies that starts from $y / h=1.25$ to the upper wall of the working domain points out that the far fields of the flow are strongly affected adversely by using the small number of mesh elements.

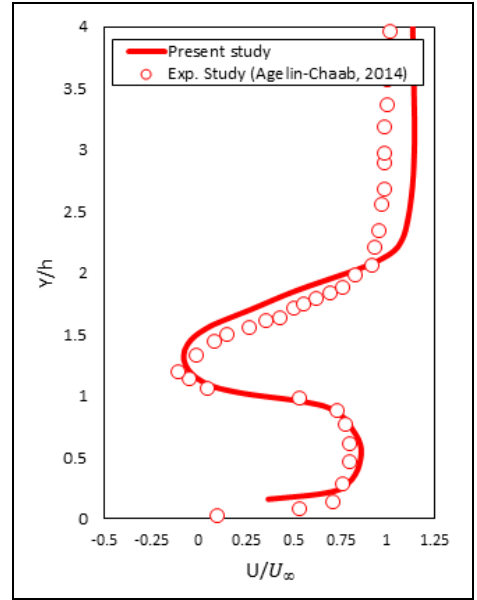

(a)

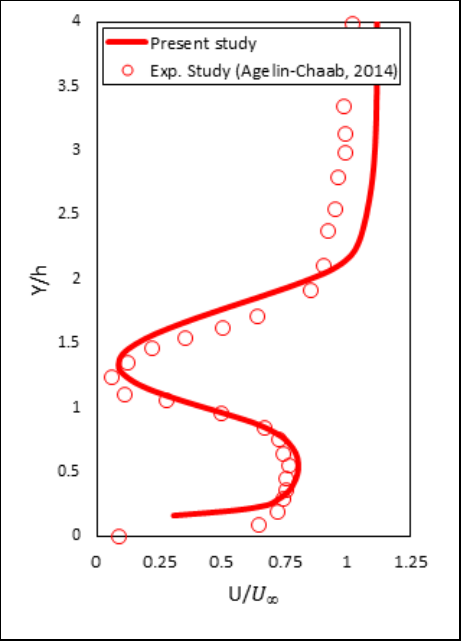

(b)

Figure 5: Comparison of the present study with the experimental data of Agelin-Chaab, 2014 [1] at a) $x / h=0.5, b$ ) $\mathrm{x} / \mathrm{h}=1.0$.

Contours of static pressure distribution on Case 1 and other modified models indicate that the pressure is very high on the grill (front of the hood) of the vehicle in which the velocity of the flow becomes zero and stagnation point is created as shown in Figure 6. This is the region where the flow encounters with the truck first. The pressure then decreases gradually towards the corners of front surfaces and becomes minimum at the intersection of the windshield and cab top and then increases towards the end of the cab top without changing its magnitude. It is seen that as the reference model is modified from Case 1 to Case 4 the pressure on the bed surfaces decreases. Flow separation is expected to occur in the regions in which the static pressure is low. These regions are the sharp edges of the truck, the edges of the cab, and grill junctions with side-frame of the hood and edges of the windshield. The pressure difference created between two edges (front and back) of the body causes the net aerodynamic force acting on the vehicle to generate a drag against the motion of the vehicle. 


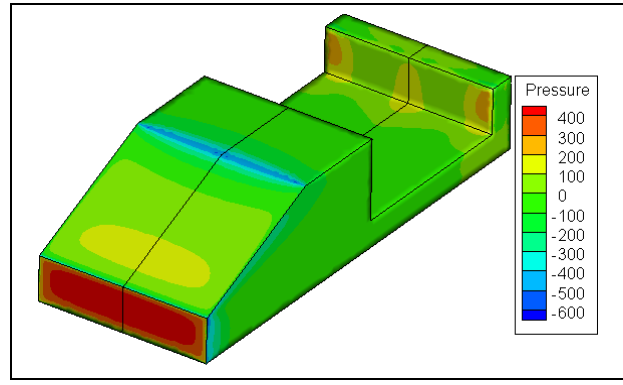

(a)

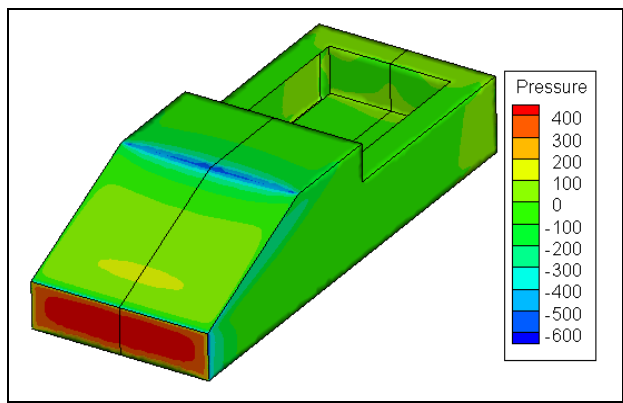

(b)

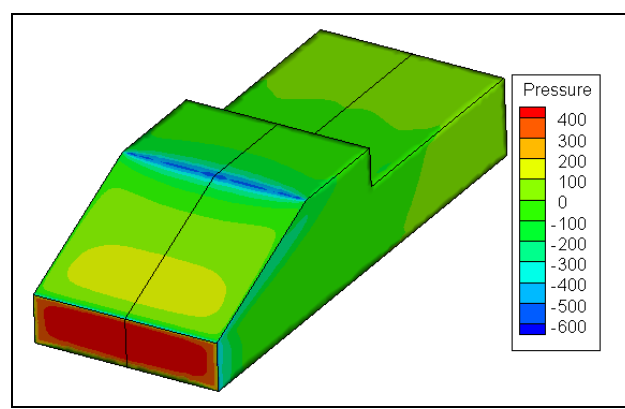

(c)

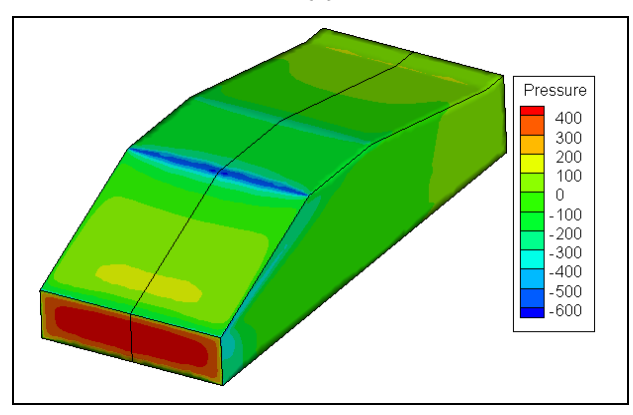

(d)

Figure 6: Static pressure contours (in Pa) on the models at $\mathrm{Re}=312000$ for. (a): Case 1. (b): Case 2. (c): Case 3. (d): Case 4.

Skin friction distributions on the pick trucks are shown in Figure 7 where red and blue colors represent attached and detached flows, respectively. Flow separations as indicated in red-shaded color were observed on the surfaces mainly at the intersection of the windscreen and top part of the front section of all models, intersection of cab roof and bed box (except Case 4) and rear end of the bed gate due to approximately zero shear stress caused by adverse pressure gradient as reported in the literature [19]. It is seen that the Case 4 is the best configuration among the models because it contains few areas of blue-shaded colors which mean minimum flow separation.

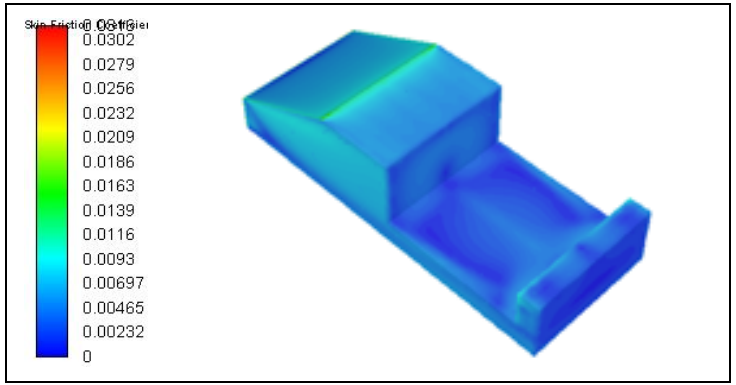

(a)

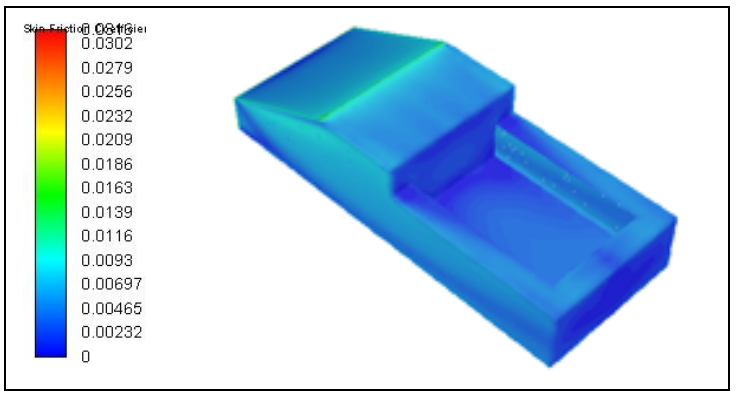

(b)

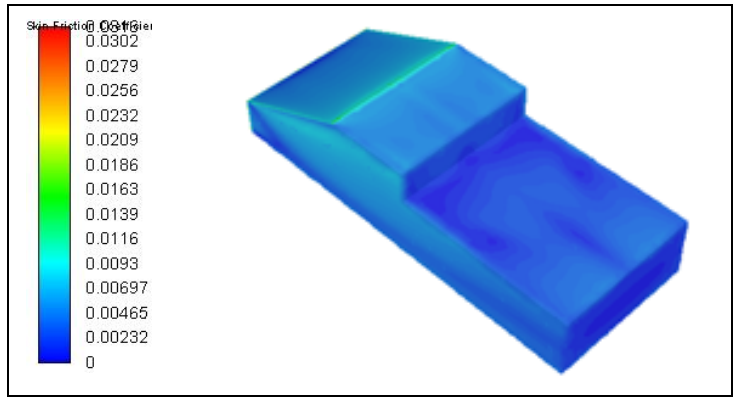

(c)

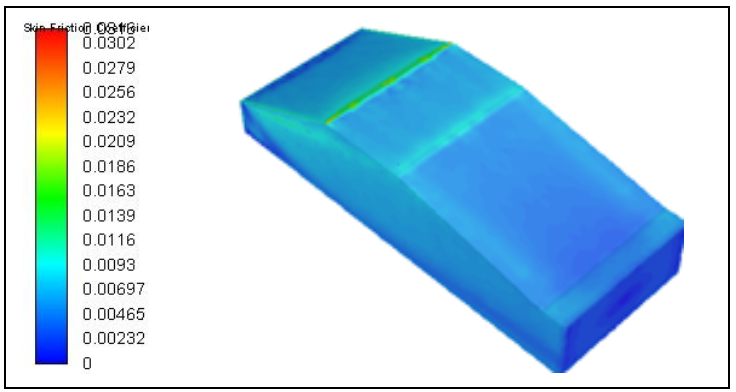

(d)

Figure 7: Skin friction coefficient for. (a): Case 1. (b): Case 2. (c): Case 3. (d): Case 4 at $\mathrm{Re}=312000$.

Flow characteristics behind the modified pickup trucks are shown in Figure 8. The flow separates behind the truck and resulting a large-scale counter-rotating vortex pair (CRVP). The development of such CRVP along the streamwise direction is shown at the stations of $\mathrm{x} / \mathrm{h}=0,1,2,4,8$ and 16 where $\mathrm{x} / \mathrm{h}=0$ intersects with the tailgate. The flow fields at each station make it clear that the size of the CRVP increases along with the horizontal $\mathrm{x}$-direction from the tailgate to the exit of the computational domain. At $\mathrm{x} / \mathrm{h}=0$ there are small bubbles formed beneath and on the tailgate. Then, they merge at $\mathrm{x} / \mathrm{h}=1$ and keep growing in size towards the next stations. However, the formation of the CRVP following the Case 4 seems quite 
different since two bubbles form at $\mathrm{x} / \mathrm{h}=2$ and merge at $\mathrm{x} / \mathrm{h}=3$. In the present study, the gap between the ground and the bottom surface of the pickup truck is kept constant and flow structure due to this gap is not investigated, however, the reader may get knowledge in detail about the flow over and beneath a solid body from this one [20].

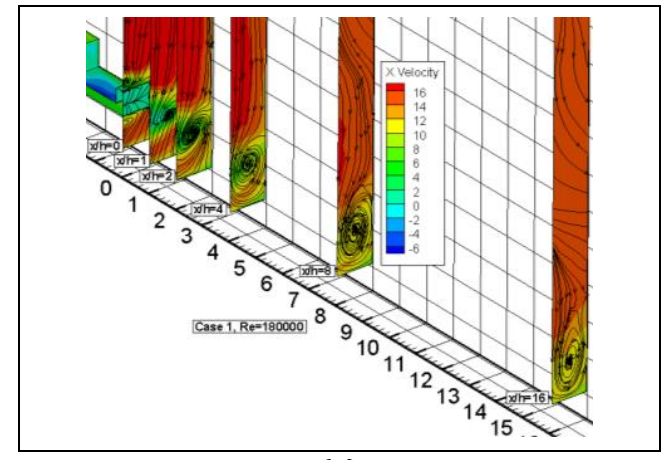

(a)

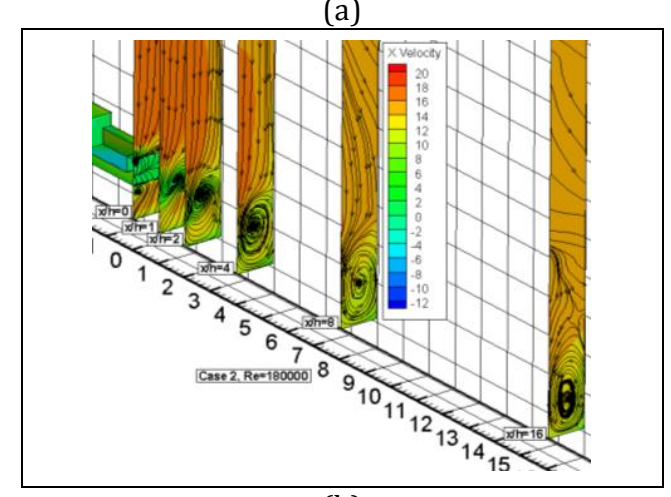

(b)

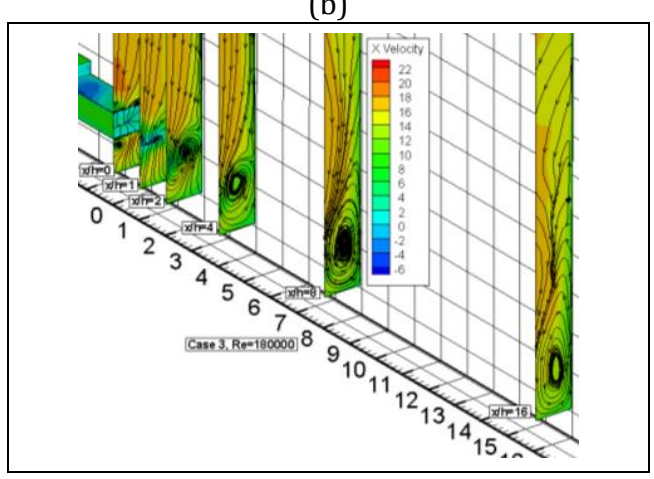

(c)

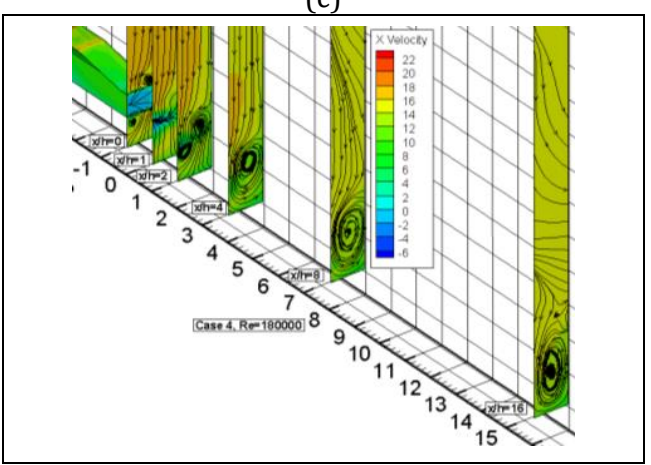

(d)

Figure 8: Flow structure after the pickup truck. (a): Case 1.

(b): Case 2. (c): Case 3. (d): Case 4 at $\mathrm{Re}=180000$.

Streamlines obtained at symmetry plane are depicted in Figure 9. It is clear that the aft flow fields of the pickup trucks with the box open at the top are quite complex. The flow passing over the cab roof encounters the sudden transition to the rear cab surface for the first three cases, unable to negotiate a nearly $90^{\circ}$ turn where it detaches from the rear cab surface. Such flow motion causes the formation of a complex flow pattern of recirculating flow in the box. The modification and particularly the rear section of the box affects the flows at the rear of the cab. When the sides of the box are closed a large recirculating bubble occurs in the box. Using a tonneau eliminates that bubble and reduces the aerodynamic drag as shown later. However, instead of single bubble form after the tailgate when the box is open, there are two bubbles behind the tailgate. It is seen that the tonneau reduces the declination angle of the backflow and consequently the aerodynamic drag.

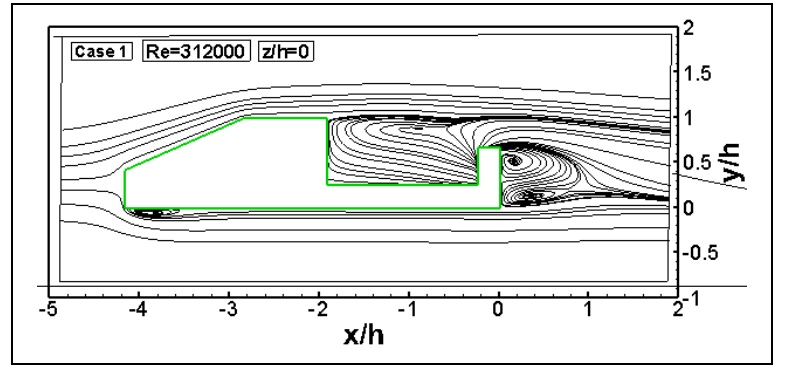

(a)

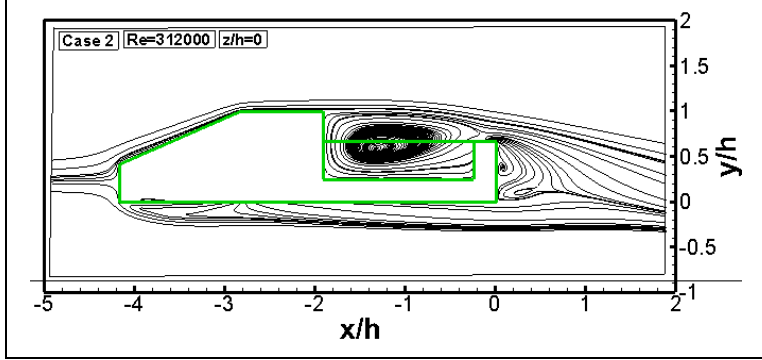

(b)

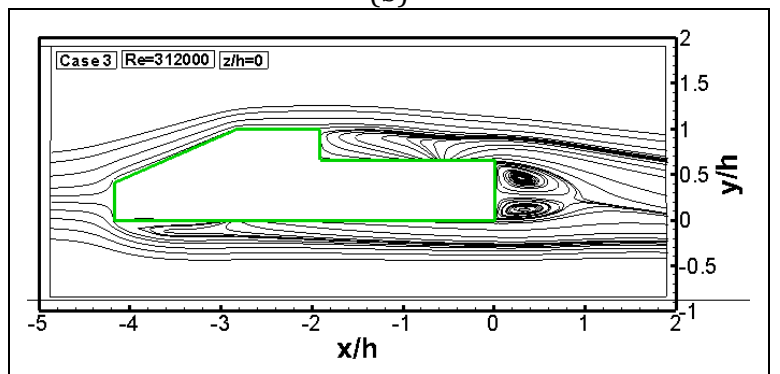

(c)

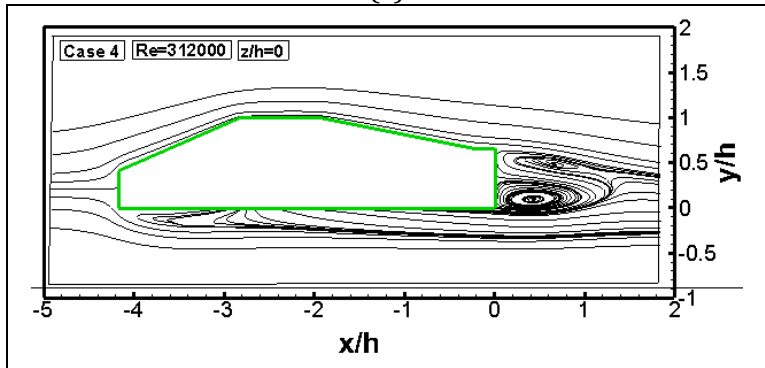

(d)

Figure 9: Flow over the trucks at symmetry plane. (a): Case 1.

(b): Case 2. (c): Case 3. (d): Case 4 at $\mathrm{Re}=312000$.

Flow fields obtained at $\mathrm{y} / \mathrm{h}=0.5$ is shown in Figure 10 . The existence of the recirculation bubbles inside the bed for Case 1 is clearly seen. Closing the sides of the box reduces the size of 
these bubbles in $\mathrm{x}$ - and z-directions and causes the small-scale bubbles to move to the corner of the tailgate. Since the fluid cannot enter to the box from the sides anymore, it keeps it way through the side walls of the box when the sides are closed and encounters with the backflow, resulting in the formation of a small-sized bubbles behind the tailgate.

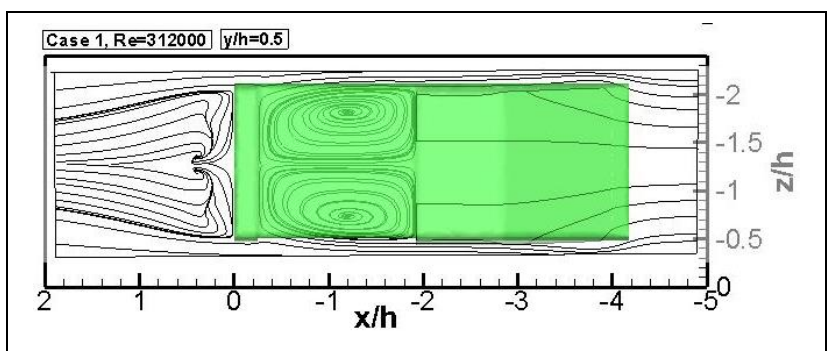

(a)

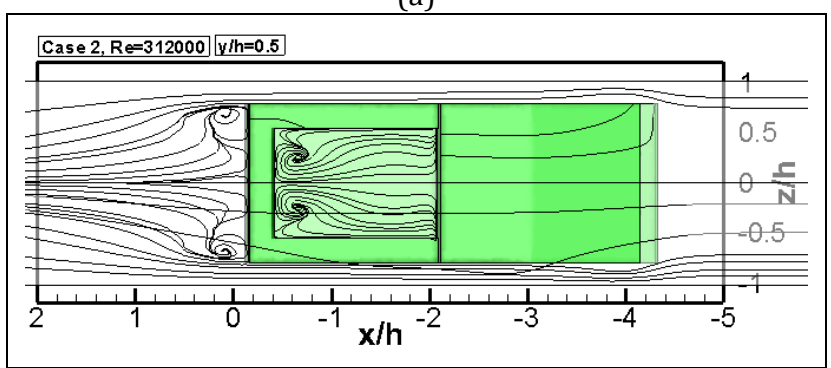

(b)

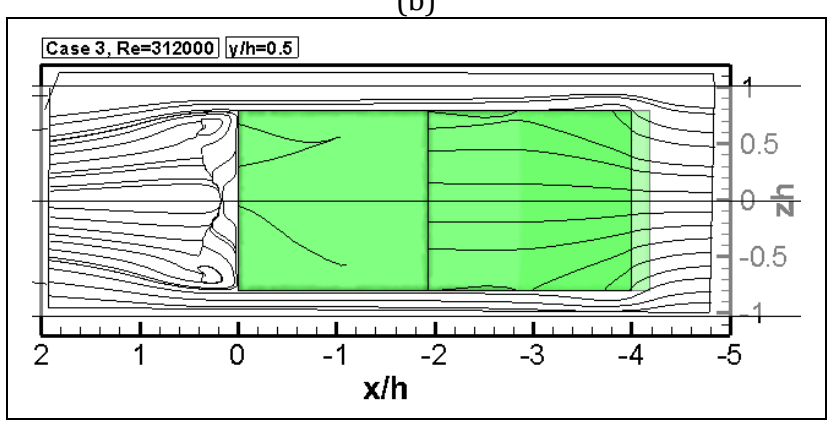

(c)

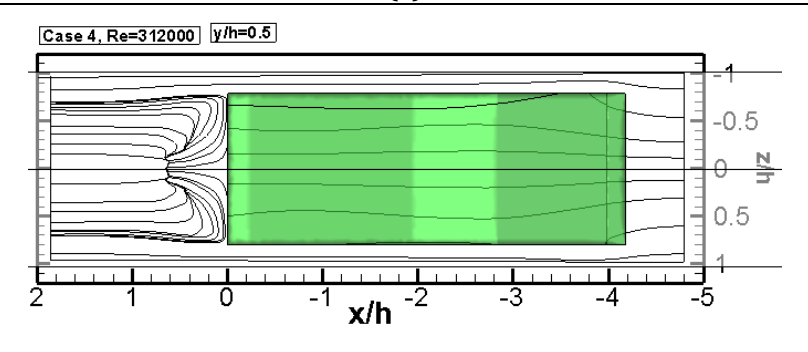

(d)

Figure 10: Flow structure at $\mathrm{y} / \mathrm{h}=0.5$. (a): Case 1, b) Case 2, c) Case 3, d) Case 4 at $\operatorname{Re}=312000$.

Flow fields behind the pickup trucks at Case 3 and 4 are quite similar, however, the flow is straighter following the modified model in Case 4 since the flow can able to flow smoothly over the cab and the box. The station of $y / h=0.75$ is a section of the box and the behavior of the flow at that horizontal plane is demonstrated in Figure 11. Instead of the bubbles in the box and behind the tailgate it seems that only two but larger bubbles form over the box for Case 1. Effects of the side walls on the size of the bubbles are introduced in Figure 11b where the bubbles form next to the roof of the cab. Covering the box with the tonneau yields a relatively small-sized bubble with respect to the previous cases. Since the fluid does not detach from the roof and flows smoothly over the canopy cover from the roof to the tailgate, no any bubbles are seen in Case 4. ,

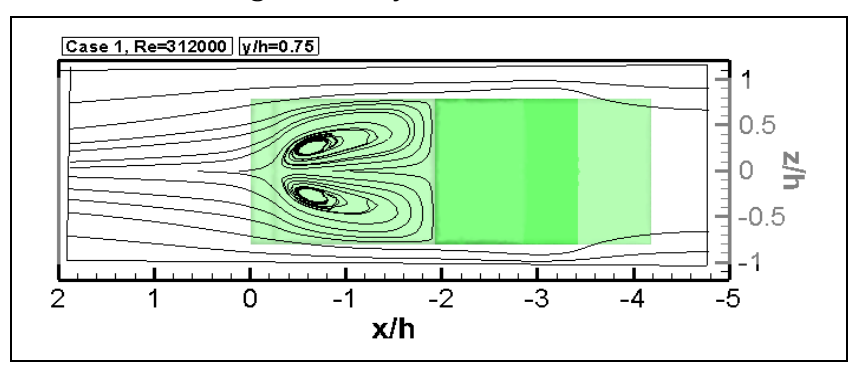

(a)

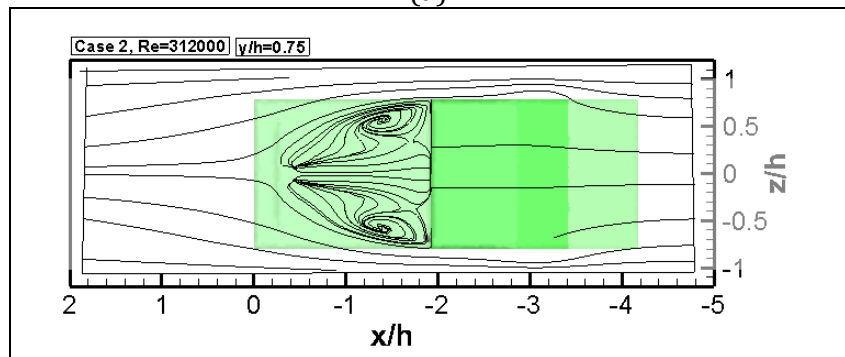

(b)

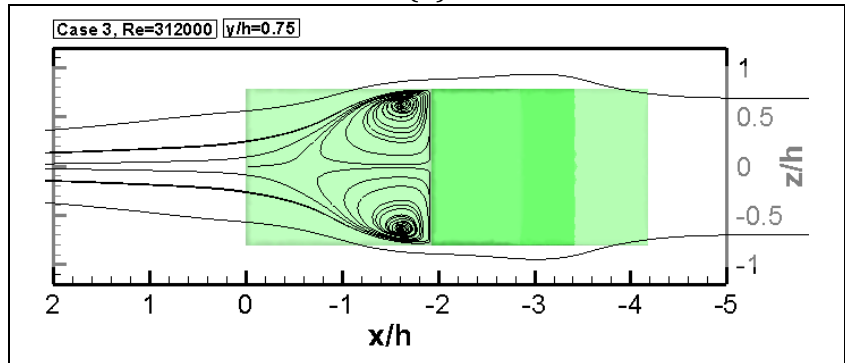

(c)

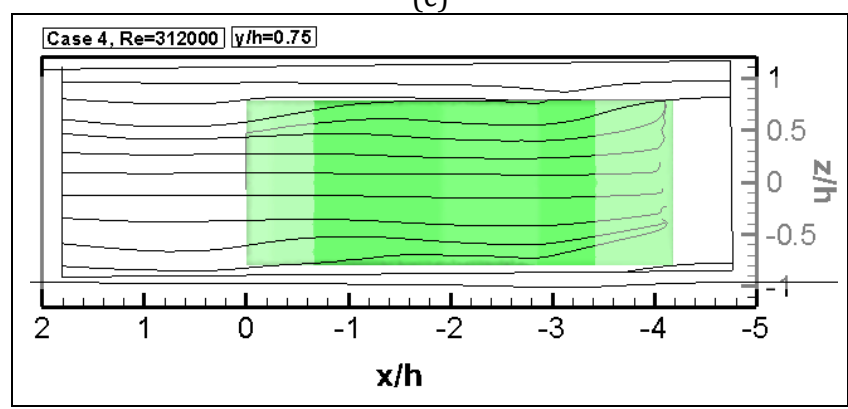

(d)

Figure 11: Flow structure at $\mathrm{y} / \mathrm{h}=0.75$. (a): Case 1. (b): Case 2. (c): Case 3. (d): Case 4 at $\mathrm{Re}=312000$.

The non-dimensional pressure coefficient $\left(\mathrm{C}_{\mathrm{p}}\right)$ distributions on the symmetry planes of the reference (Case 1) and modified pickup trucks are presented in Figure 12a. The reference model was modified by closing the sides of the box first. Then the box was covered with a tonneau and finally, the box was completely closed with a canopy from all sides and merged from the cab roof to the tailgate. Since the top surfaces of the models are quite different from the other surfaces the pressure coefficient distributions on top surfaces are different from one another. The bottoms of the models were not changed, therefore, the pressure distributions over the bottom surfaces are the same except for some small variations. It can be concluded from the plots that the pressure distributions over the rear end of the tonneau and canopy covers are higher than the pressure distributions under the body of the trucks. Such difference in 
the pressure causes a reduction in lift force of the model with tonneau cover and improvement in the Case 4.

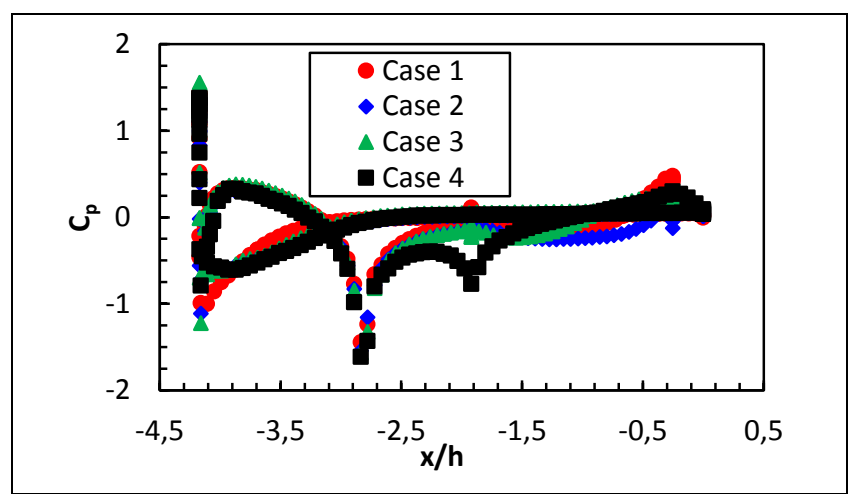

(a)

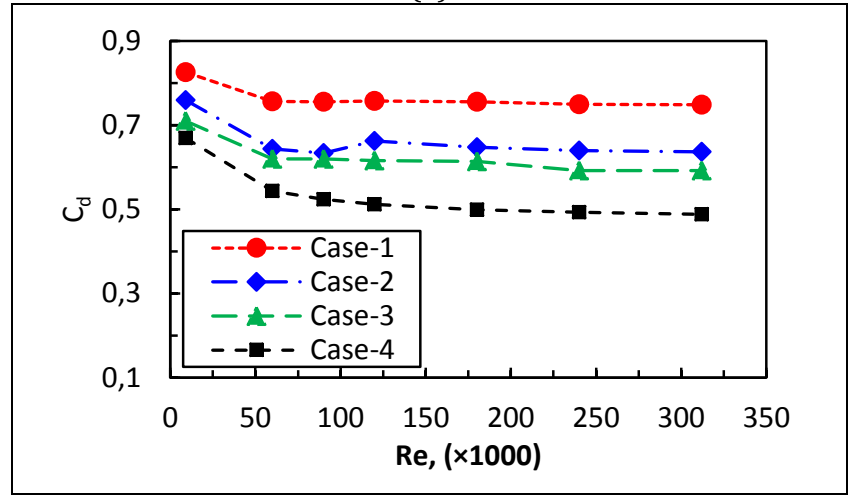

(b)

Figure 12: Pressure coefficient $\left(C_{p}\right)$ distribution over the pickups at $\operatorname{Re}=312000$. (a): and drag coefficient $\left(C_{d}\right)$ variations for different Re numbers (b).

For the reference case, the pressure distributions over and under the body are the same. Drag coefficient $\left(C_{d}\right)$ variations with Re numbers are plotted in Figure 12b. As it is expected, the drag coefficient decreases with Re number. It decreases sharply when $R e$ number increases to $R e=60000$ from $R e=9000$ and then recovers at $R e=120000$. Thereafter, it decreases very smoothly and almost flattened for further Re numbers for each cases. Diminishing two larger bubbles inside the box by closing both sides of the box leads drag reduction by $14 \%$ at $\mathrm{Re}=180000$. Using tonneau decreases drag coefficient a bit more in comparison with the open top. Although the flow detaches from the cab roof and recirculates on the closed box with a tonneau, it is clear that there is still a room to reduce the aerodynamic drag. Further improvements were achieved by closing all sides of the box and connecting the cab roof with the tailgate directly by means of a canopy cover. Effects of such modification can be seen on the drag of Case 4 which has the lowest drag coefficients at any Re number. For instance, additional $22 \%$ in drag reduction is obtained at $\mathrm{Re}=180000$.

It is obvious that there is a strong relationship between the drag force and thus the coefficient of drag and fuel consumption of the vehicle since the aerodynamic drag is proportional to the square of the driving speed as shown in Eq.1. The required power to overcome this drag is proportional to the third power of the speed since the power is the product of the drag force $\left(F_{D}\right)$ and the speed of the vehicle $\left(U_{\infty}\right)$. Therefore, reducing the drag coefficients means decreasing the fuel consumption and improving the fuel economy of the vehicle.

\section{Conclusion}

In the present study, flow fields over some modified pickup trucks were investigated numerically. Three different modifications were done on a reference pickup truck that was found in the open literature. The modification processes were done by closing the sides only and then the top of the bed of the truck in addition to the sides of the bed. Finally, the truck cab was connected to the bed cover by means of a tonneau. Effects of such variations in shape of the pickup truck on the flow field and aerodynamic drag coefficients were investigated. It was shown that when the sides of the box of the pickup truck were open to the atmosphere two large bubbles form inside the box just behind the cab roof. Regardless of the Reynolds number, the highest drag coefficient was obtained for this case. Closing all sides of the box, except the top, as done in the second case, reduces the size of the bubbles that recirculate inside the box resulting lower drag coefficient. Additional reduction in aerodynamic drag was achieved when the top of the box was covered with a tonneau. Covering all open sides of the box from the tailgate to the cab roof by a canopy reduces the drag coefficient by almost $50 \%$ in comparison with the first case. It is shown that the drag coefficient decreases with Reynolds number regardless of the cases. Since the fuel consumption of the vehicles depends on the drag force and hence the drag coefficient, reducing the drag coefficient increases the fuel economy of the vehicles. Therefore, it can be concluded that the most efficient case is the one with the bed covered by a canopy from the tailgate to the top of the cab (Case 4) while the least efficient vehicle is the reference one.

The pressure coefficient distribution show that there is a decrease in lift force of the pickup truck with tonneau and canopy cover since the pressure coefficient distribution over this case is higher than the bottom surface.

\section{References}

[1] Agelin-Chaab M. "Structure of turbulent flows over twodimensional bluff bodies inspired by a pickup truck geometry". International Journal of Heat Fluid Flow, 50, 417-430, 2014.

[2] Bayraktar S, Bilgili YO. "Effects of under body diffuser on the aerodynamics of a generic car". International Journal of Automotive Engineering Technology, 7(2), 99-109, 2018.

[3] Sudin MN, Abdullah MA. Shamsuddin SA, Ramli FR, Tahir MM. "Review of research on vehicles aerodynamic drag reduction methods". International Journal of Mechanical Engineering, 14(2), 35-47, 2014.

[4] Altaf A, Omar AA, Asrar W. "Passive drag reduction of square back road vehicles". Journal of Wind Engineering and Industrial Aerodynamics, 134, 30-43, 2014.

[5] Das P, Tsubokura M, Matsuuki T, Oshima N, Kitoh K. "Large eddy simulation of the flow-field around a full-scale heavy-duty truck". Proceeding Engineering, 56, 521-530, 2013.

[6] Chilbule C, Upadhyay A, Mukkamala Y. "Analyzing the profile modification of truck-trailer to prune the aerodynamic drag and its repercussion of fuel consumption". Proceeding Engineering, 97, 1208-1219, 2014.

[7] Turkish Statistical Institute (TUIK). "Motorized Ground Vehicles".

http://www.tuik.gov.tr/PreHaberBultenleri.do?id=2764 7, (14.12.2018). 
[8] U.S. Department of Transportation, Bureau of Transportation Statistics, National Transport Statistics 2017,

[9] Yang Z, Khalighi B. "CFD simulations for flow over pickup trucks". SAE World Congress, Detroit, Michigan, USA, 11-14 April 2005.

[10] Lokhande B, Sovani S, Khalighi B. "Transient simulation of the flow field around a generic pickup truck". SAE World Congress, Detroit, Michigan, USA, March 3-6 2003.

[11] Williams NA, Gordis JH, Leatherwood M. "Drag optimization of light trucks using computational fluid dynamics", SAE Commercial Vehicle Engineering Congress \& Exhibition, Chicago, Illinois, USA, 26-28 October 2004.

[12] Ha J, Obayashi S, Kohama Y. "Drag characteristics of a pickup truck according to the bed geometry", Proceedings of the 7th IASME/WSEAS International Conference on Fluid Mechanics \& Aerodynamics, Moscow, Russia, 20-22 August 2009.

[13] Ha J, Jeong S, Obayashi S. "Drag reduction of a pickup truck by a rear downward flap". International Journal of Automotive Technology, 12(3), 369-374, 2011.

[14] Moussa AA, Fischer J, Yadav R. "Aerodynamic drag reduction for a generic truck using geometrically optimized rear cabin bumps". Journal of Engineering, Article ID 789475, 1-14, 2015.
[15] Boyer H, Sigurdson L. "Flow visualization of light vehicletrailer systems aerodynamics", Journal of Visualization, 18, 459-468, 2015.

[16] Launder BE, Spalding DB. Lectures in Mathematical Models of Turbulence, London, England, Academic Press, 1972.

[17] Cengel YA, Cimbala JM, Fluid Mechanics Fundamentals and Applications. $4^{\text {th }}$ ed. New York, USA, McGraw-Hill Education, 2017.

[18] Sharma RB, Bansal R. "CFD simulation for flow over passenger car using tail pates for aerodynamic drag reduction". Journal of Mechanical and Civil Engineering, 7(5), 28-35, 2013.

[19] Altinisik A, Kutukceken E, Umur H. "Experimental and numerical aerodynamic analysis of a passenger car: Influence of the blockage ratio on drag coefficient". Journal of Fluid Engineering, 137, 081104-114, 2015.

[20] Bayraktar S, Yayla S, Oztekin A, Ma H. "Wall proximity effects on flow over cylinders with different crosssections". Canadian Journal of Physics, 92(10), 1141, 1148, 2014. 